Sáiz-Serrano, J. \& Parra Monserrat, D. (2017). Formación del profesorado de historia y ficción televisiva: el aprovechamiento didáctico de las series históricas en educación secundaria. Revista Electrónica Interuniversitaria de Formación del Profesorado, 20(2), 95-109.

\title{
Formación del profesorado de historia y ficción televisiva: el aprovechamiento didáctico de las series históricas en educación secundaria
}

\author{
Jorge Sáiz Serrano, David Parra Monserrat \\ Universidad de Valencia
}

\section{Resumen}

Este artículo aborda la capacidad de aprovechamiento didáctico mostrada por 72 estudiantes universitarios procedentes del Máster de Profesorado de Educación Secundaria (especialidad de Geografía e Historia) en relación con las series de televisión de temática histórica. Para ello, se ha diseñado un instrumento (un cuestionario abierto sobre ficción televisiva) orientado a examinar, por un lado, la alfabetización mediática de los futuros docentes y, por otro, su capacidad de impugnar la representación del pasado histórico nacional ofrecida por muchas de estas series y de plantear alternativas desde la óptica de una didáctica crítica. Los primeros resultados del estudio ponen de relieve la necesidad de mejorar la alfabetización audiovisual y la formación epistemológica del futuro profesorado para que sea capaz de aprovechar todo el potencial educativo de estos formatos y sus narrativas.

\section{Palabras clave}

Educación histórica; ficción histórica televisiva; formación del profesorado; narrativa nacional.

Jorge Sáiz Serrano, Jorge.saiz@uv.es, David Parra Monserrat, David.parra@uv.es, Departamento de Didáctica de las Ciencias Experimentales y Sociales, Facultad de Magisterio, Universidad de Valencia, Avda. dels Tarongers, 4, 46022, Valencia.

Este trabajo forma parte del proyecto de investigación financiado por el Plan Nacional de I+D+i del MINECO (EDU2015-65621-C3-1-R) y cofinanciado con fondos FEDER de la UE. 


\title{
History Teachers Training and Television Fiction: didactical use of historical series in secondary education
}

\begin{abstract}
The main aim of this paper is to analyse the capacity for didactic use shown by 72 students coming from the Master's Degree in Secondary Education Teaching (specialization in Geography and History) in relation to historical television series. To this end, a tool (an open questionnaire on television fiction) has been designed to examine, on the one hand, the media literacy of future teachers and, on the other hand, its capacity to refute the representation of the national historic past offered by many series and to propose alternatives from the perspective of a critical didactics. The first results of the study highlight the need to improve audiovisual literacy and epistemological training of future teachers that they may be able to take full advantage of the educational potential of these formats and their narratives.
\end{abstract}

\section{Key words}

History Education; Historical TV Series; Teacher Training Program; National Narrative.

\section{Introducción}

La presencia de la historia como producto cultural de masas ha crecido en España recientemente de la mano de series de televisión que biografían personajes tradicionales (Isabel, Carlos rey, emperador), recrean escenarios del siglo XX español (La señora, Amar en tiempos revueltos, Cuéntame cómo pasó) o se ambientan en contextos históricos fácilmente identificables por el gran público (El Ministerio del Tiempo) (Rueda \& Coronado, 2009 y 2016). Este perfil de series televisivas es una manifestación más de los usos públicos de la historia que, desde hace años, han merecido la atención de la historiografía (Carreras, 2003; McMillan, 2010). Como producto de consumo lúdico y de entretenimiento su amplia difusión aproxima contenidos y escenarios históricos a todo tipo de espectadores, entre ellos docentes y estudiantes de diferentes niveles educativos. Este uso público de la historia convive, y a la vez compite, con el conocimiento histórico escolar y, en ocasiones, puede constituir una de las fuentes de información más potentes sobre el pasado histórico.

En este artículo pretendemos indagar sobre las respuestas que puede ofrecer la didáctica de la historia y las Ciencias Sociales para el aprovechamiento pedagógico de estos nuevos recursos audiovisuales, fácilmente accesibles gracias a la reproducción digital o streaming así como al contenido en forma de narrativas transmedia disponible en las webs de las propias series. ¿Es posible la utilización didáctica de estos productos en la enseñanza y aprendizaje de la historia en educación secundaria? Una vía para abordar esta cuestión es centrarla en el perfil del futuro profesorado de Geografía e Historia en formación, en gran medida jóvenes más habituados al consumo de estas series y que, potencialmente, pueden hacer uso de las mismas en sus prácticas docentes.

Atendiendo a todas estas cuestiones, en el trabajo presentamos unos breves fundamentos teóricos para aproximarnos al potencial didáctico de dichas series desde los enfoques de la historia cultural y la didáctica crítica. Desde esta perspectiva examinamos una serie en 
concreto, El Ministerio del Tiempo', para valorar las posibilidades de aprovechamiento didáctico planteadas por el futuro profesorado de secundaria (estudiantes del Máster de Profesor de Educación Secundaria en la especialidad de Geografía e Historia de la Universidad de Valencia) a partir de los resultados de un cuestionario abierto. Nuestro objetivo es comprobar si la formación historiográfica de los futuros docentes les capacita para apreciar y usar las potencialidades formativas del relato audiovisual y si disponen de la alfabetización visual e histórica pertinente para comprender relatos televisivos y aprovecharlos para la enseñanza de la historia. Singularmente nos interesa conocer si son capaces de leer los discursos de nacionalismo banal español (Billig, 1995; Archilés, 2015) presentes en las mismas.

\section{Ficción histórica televisiva, historia cultural y didáctica crítica: nuevos recursos y nuevos retos pedagógicos}

Conviene comenzar cuestionándonos hasta qué punto la ficción histórica televisiva, como producto cultural, es aprovechable en la enseñanza de la historia en secundaria. Ello nos lleva a plantearnos dos problemas: por un lado, qué representación del pasado histórico ofrecen dichas series como relato (estereotipos de contenido, usos del tiempo histórico, etc.); por otro, en qué medida la imagen audiovisual se considera un recurso didáctico útil y valorado en la enseñanza de la historia en relación con otros recursos, singularmente los textos académicos.

Podemos considerar el relato audiovisual, desde el cine a las series de televisión, como un complejo producto cultural que tiene su propia estructura comunicativa cuya interpretación exige una comprensión del significado cultural que se le otorga en las sociedades contemporáneas. De ello se ha ocupado desde hace décadas la historia cultural examinando las relaciones entre imágenes, cine e historia (Bell \& Gray, 2007; Bolufer, Gomis y Martínez, 2015; Burke, 2001; Ferro, 2008; Martínez Gil, 2013; Rosenstone, 1997 y 2005). Esta aproximación ha permitido contextualizar y comprender la imagen audiovisual como una representación del pasado, sean películas, documentales o series televisivas, como también lo son los textos históricos (testimonios coetáneos) o los historiográficos (los escritos de historia). Ningún relato audiovisual ni textual puede reproducir un pasado fidedigno, siempre hay una mediación cultural para acceder a él. Y aunque desde la historia académica se llega a consensos y acuerdos en el conocimiento y comprensión del pasado histórico, epistemológicamente dicho pasado no es la representación textual o audiovisual que podamos hacer del mismo (Gunn, 2011; Jenkins, 2009) Esta aproximación socio-cultural al cine y a las series televisivas de contenido histórico siempre es necesaria si queremos relativizar su papel como imagen o representación fidedigna del pasado, que aunque es obvio que en muchas ocasiones logre excelentes ambientaciones o reconstrucciones, siempre exige una decodificación previa.

Paralelamente, desde un enfoque pedagógico, las innovaciones tecnológicas en la esfera cultural, como internet o la televisión digital, introducen nuevos retos para la enseñanza/aprendizaje del pensamiento histórico. Una didáctica crítica de la Historia debe

\footnotetext{
${ }^{1}$ Tal y como señala Peris (2016), esta serie ha sido una de las grandes sorpresas de la televisión española reciente. Un equipo de funcionarios, pertenecientes a diversas épocas de la Historia de España, se encarga de garantizar que no haya alteraciones en los hechos históricos tal y como los conocemos. Así, dentro de este ministerio hay una compleja red de pasadizos que conectan el presente con cualquier periodo de la historia de España, como si "ser español" fuera una condición natural de los individuos que han habitado este territorio desde hace milenios (Rueda Laffond \& Coronado, 2016)
} 
desarrollar nuevas formas de abordar dicho pensamiento para fomentar una perspectiva compleja sobre la relación entre los hechos históricos y la manera como se reproducen y recuerdan a través de narrativas articuladas en diversos formatos (audiovisual, textual, icónico, etc.). El profesorado de Geografía e Historia, en este sentido, debería ser capaz de educar a los estudiantes para que sepan interpretar el lenguaje de la memoria pública y leer la historia no como un mero acto de recuperación del pasado, sino como un dilema de incertidumbres sobre el mismo, siempre condicionado por las relaciones saber/poder del presente (Giroux, 2001; Tadeu da Silva, 1994).

En este estudio, lo que nos interesa es ver si los futuros docentes son capaces de cuestionar las narrativas maestras de nación que históricamente ha construido el currículum y que ahora se ven reforzadas/reelaboradas por los medios de comunicación de masas. El discurso de buena parte de las series televisivas que abordan el pasado histórico de España está ampliamente condicionado por contenidos transversales de una narrativa nacional codificada en el siglo XIX y difundida a gran escala durante el franquismo. Esta narrativa fundamentaba el origen de España y de los españoles en periodos pre-contemporáneos, con hitos como la Reconquista, la unificación de los Reyes Católicos o el mito del imperio español, entre otros (López Facal, 2008; López Facal y Sáiz, 2016; Maestro, 2005; Parra, 2012; Sáiz y López Facal, 2016). Dichos contenidos perviven con fuerza de forma transversal en ámbitos extraescolares, probablemente fruto de su uso en la literatura y, especialmente, en los medios de comunicación de masas. De hecho, su presencia se haría patente en las series de televisión de contenido histórico como corroboran diversos estudios centrados en la presencia de discursos del nacionalismo banal español en series de televisión desde el Franquismo hasta la actualidad (Rueda, 2014; Rueda y Coronado, 2009, 2016; Rueda et al, 2009; Peris, 2012, 2015 y 2016). Aunque muchas de las series televisivas de inspiración histórica ofrezcan recreaciones de escenarios y contextos del pasado susceptibles de un aprovechamiento escolar, el uso didáctico de las mismas exigiría un esfuerzo de deconstrucción por parte de los docentes en una doble dirección. Por un lado, impugnar aquellos hitos de la narrativa nacional que sobreviven con fuerza en la cultura e imaginario popular; por otro, cuestionar una concepción epistemológica del pasado histórico muy tradicional basada en una visión teleológica y claramente positivista del conocimiento.

Por tanto, una didáctica crítica de la Historia debería incorporar las estrategias de deconstrucción de los relatos nacionales que han sido desarrolladas recientemente en los campos teóricos del postestructuralismo y de los estudios culturales (Tadeu da Silva, 2001). Esta dimensión crítica no consiste en discriminar lo "falso" de lo "auténtico" (la crítica cultural actual no trata de discernir una cuestión de "verdad" o "falsedad"), sino de entender qué hay detrás de determinadas representaciones y discursos que tienden a naturalizarse y que, por tanto, son muy difíciles de cambiar.

Partiendo de esta doble fundamentación, en historia cultural y en didáctica crítica, en este estudio defendemos un aprovechamiento didáctico de la ficción histórica televisiva y, por extensión, del relato audiovisual (cine histórico o documental) que vaya más allá de un uso ilustrativo como simple ambientación de un contexto histórico, pero subsidiario respecto al relato verbal-textual, que seguiría siendo la forma hegemónica de difusión del conocimiento escolar. Esta dimensión descriptiva es similar al aprovechamiento que suele hacerse de la imagen en los manuales escolares de historia donde su presencia tiende a asociarse a un rol de ilustración para el refuerzo de los textos allí presentes (Valls, 2007; Sáiz, 2015; Bel, 2016) Aquí defendemos un uso crítico del relato audiovisual como documento, una utilización como recurso didáctico y producto cultural que implique una doble tarea. En primer lugar, como recurso, su integración igualitaria y no subsidiaria con otros (sobre todo textuales) promoviendo un aprendizaje multimedia donde se aprovechen equilibradamente 
todo tipo de fuentes (Wisley y Ash, 2005). En segundo lugar, como producto cultural, un empleo del relato audiovisual que parta de la necesaria decodificación previa del mismo por parte del profesorado. Ello debe permitir a los docentes comprender los condicionantes histórico-culturales que crean el relato audiovisual, en nuestro caso las series de televisión de contenido histórico, como resultado de un determinado contexto social, cultural y político. En este sentido, conocer el origen y el proceso de construcción de esos relatos y representaciones resulta fundamental para poder impugnar estereotipos de contenido y usos del tiempo histórico, así como para desnaturalizar narrativas maestras nacionales. Ello pasa por plantear una iniciación a la alfabetización audiovisual que, en el caso del futuro profesorado, debería incorporar una formación epistemológica en historia cultural. A nuestro juicio, es desde esta perspectiva crítica desde donde podemos aprovechar adecuadamente la ficción histórica televisiva como recurso didáctico para el aprendizaje de la historia.

\section{Metodología: objetivos, muestra y diseño del instrumento}

Como ya hemos señalado, el objetivo del presente trabajo es analizar la capacidad de los futuros docentes de Geografía e Historia en Secundaria para impugnar determinadas visiones y relatos del pasado nacional presentes en las series de televisión de temática histórica y plantear un uso didáctico crítico de las mismas.

Para ello, se elaboró un cuestionario que fue cumplimentado por 72 estudiantes del Máster de Formación de Profesorado de Educación Secundaria de la Universidad de Valencia, 33 del curso 2015/16 y 39 del 2016/17. La muestra tuvo un carácter no probabilístico, puesto que se escogió de manera deliberada a futuros docentes de Geografía e Historia; pero sí casual, ya que la selección se hizo a partir de individuos a los que se tenía un fácil acceso (Flick, 2007).

Para la validación del instrumento se recurrió a expertos en Didáctica de las Ciencias Sociales procedentes de tres universidades españolas, a los que se facilitó una encuesta para valorar de 1 a 4 el diseño y aspectos formales así como los contenidos y su relación con la consecución de los objetivos, siguiendo algunos de los pasos propuestos por Alfageme et al. (2010). También se les pidió una valoración cualitativa del mismo mediante comentarios y recomendaciones. Todos los ítems recibieron una puntuación media que sobrepasaba el 3 y las observaciones recibidas fueron tenidas en cuenta tanto para la confección del instrumento definitivo como para el análisis de los resultados obtenidos.

El instrumento se organizó en dos grandes bloques. El primero se centraba en el consumo de series de televisión por parte de los estudiantes ("¿Ves actualmente, o has visto en los últimos años, alguna serie de televisión de temática histórica? ¿Cuáles y con cuánta frecuencia?”) y en los posibles usos didácticos que éstos les veían (“¿Consideras que alguna de estas series puede ser utilizada para la enseñanza/aprendizaje de la Historia en Secundaria y Bachillerato? ¿Piensas que ofrecen contenidos históricos adecuados para el alumnado de Secundaria/Bachillerato? ¿Por qué?”). Las preguntas pretendían, por un lado, analizar la valoración que hacían de los contenidos históricos y los enfoques historiográficos presentes en dichas series y, por otro, su capacidad de impugnar determinados estereotipos e hitos del relato histórico nacional a partir de ejemplos concretos (imágenes) de series como Isabel (véase Imagen I). 

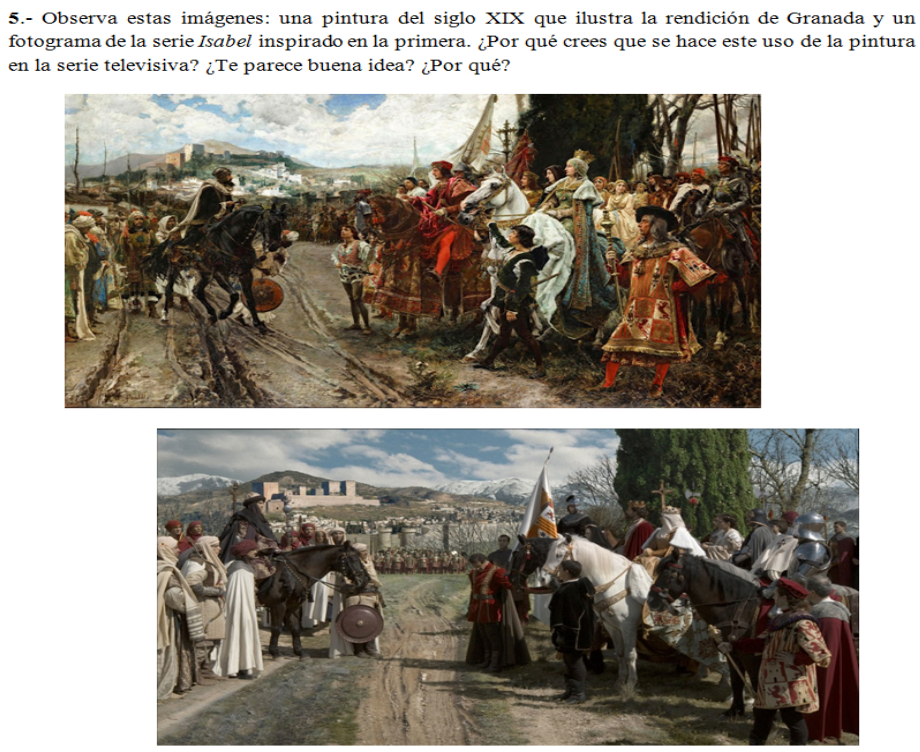

Imagen I. Pregunta del cuestionario basada en el uso de una pintura historicista y su recreación en un fotograma de la serie Isabel

La segunda parte del instrumento, centrada exclusivamente en la serie El Ministerio del Tiempo, permitía abordar los mismos aspectos de una manera más concreta. Así, se les preguntaba por los episodios y momentos elegidos en la ficción y su posible uso didáctico ("¿Utilizarías esta serie de televisión como material didáctico en las clases de Historia de España? ¿Con qué sentido/utilidad? En la serie se visitan determinados episodios históricos. ¿Por qué crees que se eligen esos y no otros?”). Con ello buscábamos conocer su capacidad crítica para cuestionar planteamientos epistemológicos y los usos tradicionales del conocimiento histórico contenidos en la serie (Rueda \& Coronado, 2016).

El cuestionario finalizaba con un ejercicio escrito en el que se les pedía que se pusieran en el papel de guionistas y elaboraran un capítulo de El Ministerio del Tiempo que pudiera utilizarse en una clase de Historia de España, lo cual implicaba la elaboración de un relato contextualizado en una época y protagonizado por unos personajes. El uso de este tipo de narrativas históricas es un recurso idóneo para evaluar el peso y la incidencia de determinados contenidos de primer orden (personajes, fechas, acontecimientos seleccionados) y discursos (a veces cuestionados en la teoría pero reproducidos en la práctica) así como de determinados metaconceptos históricos que remiten a una determinada representación del pasado y de la disciplina (Seixas \& Morton, 2013). La mayoría del alumnado habría aprendido los principales contenidos históricos a través de unas narrativas maestras que afloran cuando se les pide la elaboración de una síntesis histórica de estas características, ya que les obliga a crear unos criterios de inclusión y exclusión, a poner el énfasis en unos usos u otros, etc. (Foster, 2012; Chartier, 2007). Como señala Rüsen (2005), las operaciones narrativas exigen organizar aquello que se va a narrar y aportan información sobre los esquemas mentales y las representaciones de aquel que narra. Por tanto, el análisis de narraciones elaboradas por futuros docentes resulta de gran utilidad para detectar la presencia de determinados estereotipos o sesgos que, en ocasiones, pueden resultar un obstáculo para una comprensión rica del pasado y la implementación de una didáctica crítica de la historia (Sáiz \& Gómez, 2016).

El análisis de las respuestas de los estudiantes ha sido trabajado desde un enfoque cualitativo mediante un procedimiento de codificación abierta que ha dado lugar a una serie 
de categorías. La información se ha recogido y analizado en la base de datos Filemaker Pro, lo que ha permitido ir perfilando las distintas categorías y ha facilitado el procesamiento de los resultados.

\section{Resultados y su discusión}

La investigación se inició preguntando a los integrantes de la muestra por el consumo que hacían de series de temática histórica. Nos interesaba averiguar con qué frecuencia los futuros docentes se aproximaban a estos productos culturales y cuáles eran, en concreto, las series con un mayor grado de seguimiento. Como podemos observar en la gráfica I, casi la mitad de los encuestados había consumido recientemente, o veía en ese momento, entre 3 y 4 series relacionadas, de un modo u otro, con la Historia. Muy pocos señalaban un consumo mayor y sólo siete indicaban que no veían ninguna.

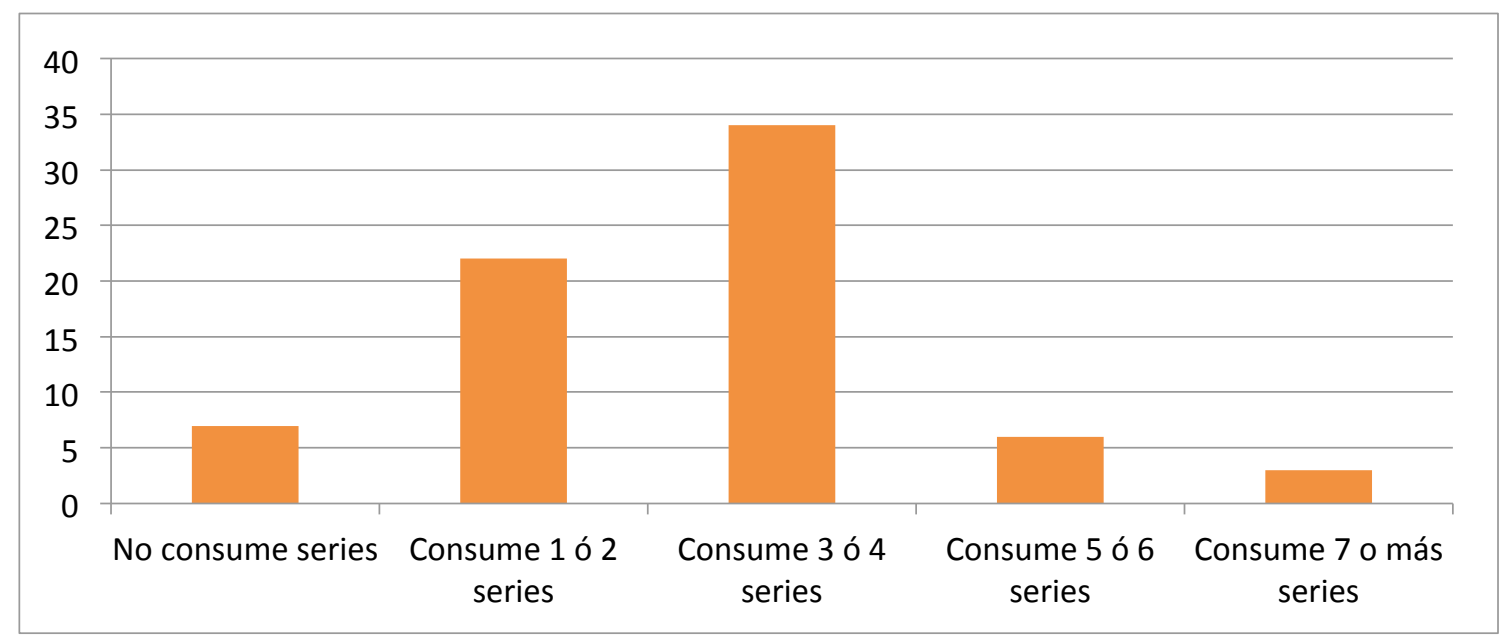

Gráfica l. Consumo de series por número de estudiantes

En la Gráfica II se recogen aquellas series que han sido citadas por tres o más integrantes de la muestra. Si atendemos al contenido, apreciamos una gran variedad temática y cronológica. Seis de ellas centran su argumento en la Historia de España o en algún episodio que haya tenido lugar en la Península Ibérica. Es el caso de las tres más destacadas y de dos de las series por las que, posteriormente, se les pregunta. Con respecto a los períodos abordados, hay un cierto equilibrio entre las distintas épocas; así, cuatro series se desarrollan durante la Antigüedad, otras cuatro durante la Edad Moderna y cuatro más durante la época contemporánea. Dos son las series ambientadas en la Edad Media y una en un mundo de ficción medievalizado. Finalmente, tres de las producciones reseñadas por los estudiantes transcurren en distintos momentos temporales, por lo que plantean interesantes reflexiones no sólo acerca de episodios y procesos históricos, sino también de la concepción del tiempo. 


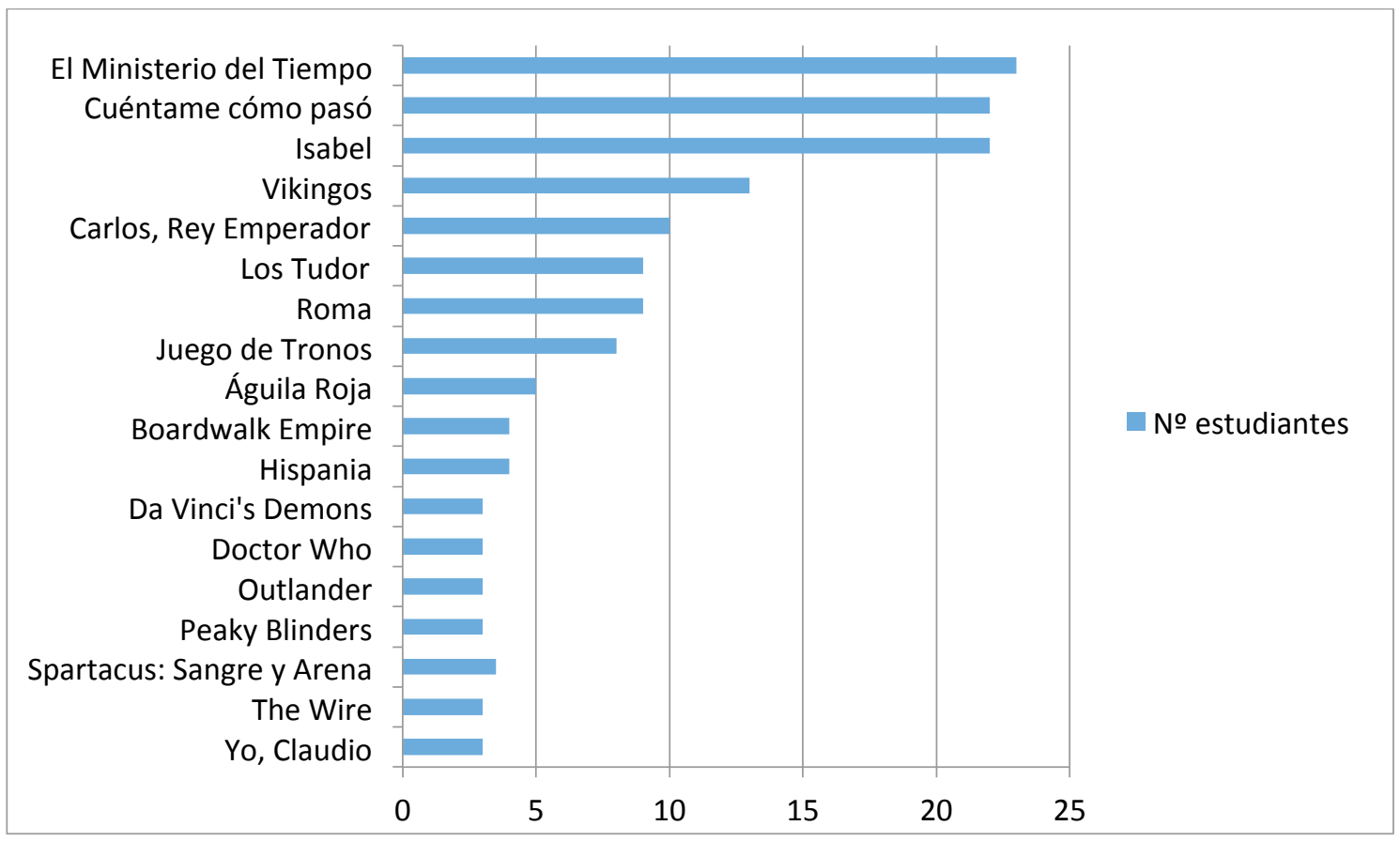

Gráfica II. Series más vistas por los integrantes de la muestra

El análisis de las respuestas relacionadas con la valoración del uso didáctico de dichas series y los argumentos utilizados nos ha permitido extraer cuatro grandes categorías. En primer lugar, podemos agrupar aquellas contestaciones que defienden directamente el interés de las mismas por su potencial ilustrativo de los contextos históricos que abordan (tipo 1). En segundo lugar, se encuentran aquellos estudiantes que recalcan explícitamente el interés de las series como recursos, incidiendo en su poder motivador como producto audiovisual, mucho más atractivo que los textos académicos (tipo 2). En tercer lugar, están quienes plantean un breve análisis del grado de veracidad o proximidad a la realidad histórica de las series demostrando únicamente un planteamiento positivista (tipo 3). Finalmente, hallamos las respuestas que demuestran una capacidad de crítica cultural de estos productos al comprender desde su estructura narrativa los estereotipos y finalidades políticas y culturales que puede haber detrás (tipo 4).

Haciendo este análisis son claramente minoritarios quienes demuestran una lectura crítica de estos recursos (tipo 4, 9 estudiantes, 12'5\%). Aunque la riqueza de sus argumentos demuestra que es posible aprender estas aproximaciones desmitificadoras, tal y como muestran los siguientes ejemplos:

"Pueden ser un recurso muy atractivo para acercar a las jóvenes a la historia. Dicho esto me gustaría señalar lo peligrosas que pueden ser [las series]: pueden simplificar y ridiculizar la historia que es algo complejo. Además es una historia de reyes en muchos casos, muy alejada de la realidad social. Mi madre concibe la historia como una sucesión de anécdotas, cotilleos, 'este era bueno, este era malo' y ello es resultado de tantas series históricas que ofrecen una visión parcial" (47, 23 años, varón)

"[Estas series sirven] para criticar los usos públicos de la Historia en clave de humor (... ) son visiones de la historia demasiado presentistas y anacrónicas, pero se puede emplear como material para invitar a la reflexión sobre las diferentes visiones" (52, 24 años, mujer) 
En contraste con estos enfoques críticos, predomina la defensa de las series como productos para lograr ambientación histórica y formas de ilustrar episodios del pasado (tipo 1, 31, 43\%) Se defiende, por ejemplo, que "reviven los hechos de distintas épocas" (35, 25 años, varón), "muestran de forma muy visual la sociedad, las tradiciones o el contexto geográfico" (72, 24, varón) o, simplemente, que ayudan a "ilustrar algún momento de la historia [...] resulta más fácil verlo plasmado en una escena que estudiarlo del libro" (70, 23 años, varón).

Esta reivindicación de su valor ilustrativo se refuerza con la defensa de su potencial como recurso audiovisual (tipo 2, 15, 20 \%). Se defiende así que "mediante un recurso audiovisual los alumnos están más receptivos y empáticos y entienden mejor el momento histórico" (15, 25 años, mujer), demostrando la sobrevaloración que existe de este recurso ya que "es la forma más atractiva para aprender historia en las aulas" (13, 23 años, mujer). De hecho, la única crítica a las series que se plantea de forma dominante es su escaso grado de verosimilitud con el pasado histórico en clave epistemológica positivista. Así, sólo se llega a matizar que "necesitan de una revisión historiográfica para contar la historia tal y como fue, sin exagerar, adornar o suavizar los hechos siendo lo más parecido posible a la realidad histórica" (5, 35 años, mujer).

Esta escasa capacidad de crítica cultural de la ficción histórica televisiva también la constatamos observando cuántos de los estudiantes son capaces de impugnar su vinculación a un determinado relato nacional tradicional. En este caso, lo hemos hecho tomando como ejemplo el ejercicio comparativo del uso de una pintura historicista (Pérez Vejo, 2014), el cuadro "La Rendición de Granada" pintado por Francisco Pradilla en 1882, y la reproducción que de la misma hizo la serie Isabel. Los datos son muy ilustrativos ya que únicamente 14 de los 72 estudiantes (19'4\%) impugnan y decodifican el relato nacional presente con argumentos como los siguientes: "se pretende algo parecido a lo que pretendían las pinturas historicistas del XIX, idealizar un acontecimiento histórico a favor de los intereses del nacionalismo" (47, 23 años, hombre); "las series utilizan cualquier elemento que haya entrado en el relato popular de la historia y más si tienen un contenido nacionalista; podemos observar continuamente la reiteración de estos tópicos" (25, 26 años, hombre). En contraste, la gran mayoría (54 estudiantes, $75 \%$ ) son incapaces de percibir esta continuidad del relato nacional e incluso reiteran los mismos argumentos de reivindicación ilustrativa de la imagen (sirven para "contextualizar mejor la obra y que el espectador se sienta atrapado en aquel momento histórico y con estos personajes" -16, 23 años, mujer-), de uso positivista por su fidelidad al pasado ("me parece buena idea ya que si se trata de una serie histórica debe estar inspirada en la verdad y no en la ficción" -6, 24 años, mujer-), o incluso del potencial visual que tienen ("a través de la pintura, de un cuadro, podemos 'leer' la historia y más en pinturas tan explícitas en cuanto temática histórica como éstas" -5, 35 años, mujer-)

Si pasamos a la parte del cuestionario dedicada a El Ministerio del Tiempo, detectamos grandes continuidades con respecto a las respuestas anteriores. Preguntados por las razones por las que la serie puede centrarse en unos episodios de la Historia de España y no en otros, sólo 25 de los 72 encuestados son capaces de detectar la presencia de una determinada carga identitaria en los hechos y personajes seleccionados así como en la forma de presentarlos:

"[se eligen unos determinados contenidos] por la tradicional consideración de la historia como una enumeración de momentos base de nuestra llamada 'identidad nacional'. Se recurre a personajes conocidos y momentos estelares como si de una telenovela se tratara, con la intención de explicar lo que también aparece en los libros de historia, como lo que es necesario conocer" (10, 31 años, mujer) 
"Intenta enlazar la historia política, diplomática y militar que el grueso del público (entre los 35-60 años hoy en día) ha recibido en el instituto. Además se busca siempre el pacto folclórico dentro de la afirmación nacional (unidad en la diversidad frente al extranjero). Ejemplo: alusiones a la laboriosidad catalana, al carácter destructivo del ejército napoleónico frente al pueblo español.. Y al mismo tiempo en la serie reside también la retórica del 'fracaso español' presente en el personaje de Julián y sus experiencias en la guerra de Cuba" (21, 29 años, varón)

Del conjunto de estudiantes, 37 asumen como "normal" la selección y la valoran positivamente atendiendo a criterios como su "relevancia", su "impacto" o su grado de difusión: "Porque deben ser hechos y personajes que más o menos suenen a la gente" (22, 22 años, varón), "Son los hechos o actores más significativos de la Historia de España" (37, 25 años, varón), "Atapuerca o Don Pelayo son dos momentos clave de la formación de nuestra historia" (48, 23 años, mujer).

Diez de los estudiantes dejan la pregunta en blanco, por lo que no son capaces de valorar los motivos que hay detrás de la elección.

Como ya hemos comentado, el cuestionario finalizaba con un ejercicio escrito en el que se pedía a los encuestados que escribiesen un esbozo de guion de un episodio de El Ministerio del Tiempo que pudiera ser utilizado en una clase de Historia. Para ello, debían seleccionar una época, unos personajes y construir un relato con una estructura determinada. Esto nos ha permitido perfilar algunas de las respuestas anteriores así como verificar el grado de alfabetización histórica de los futuros docentes. Lo que pretendíamos era valorar qué tipo de contenidos históricos aparecían en esas narrativas y desde qué enfoques eran presentados.

Si atendemos al Gráfica III nos damos cuenta del claro predominio de los enfoques tradicionales en las narrativas de los estudiantes. Ello indica, en primer lugar, que la mayoría no sólo no es capaz de impugnar determinadas representaciones presentes en los textos escolares y en los medios de comunicación de masas, sino que, además, las reproducen cuando son ellos los encargados de producir esos relatos.

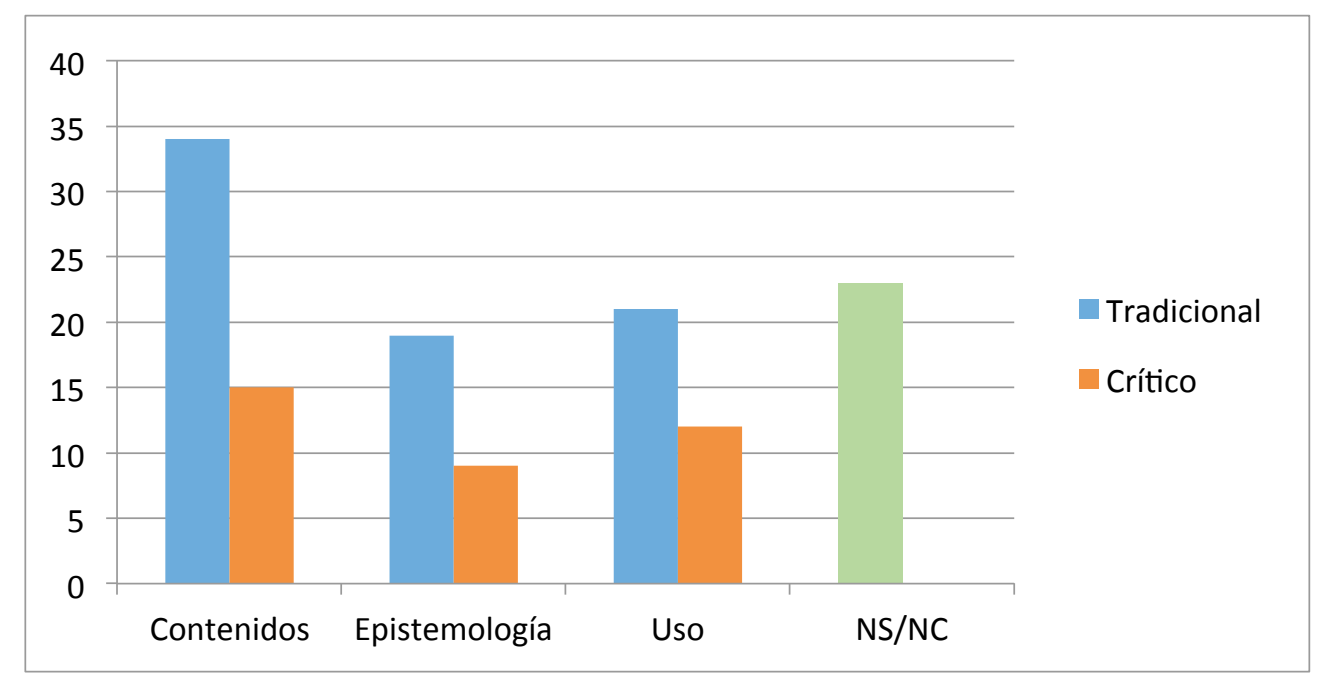

Gráfica III. Presencia de elementos tradicionales y críticos en las narrativas de los estudiantes 
En cuanto a los contenidos de primer orden presentes en los relatos, detectamos una clara presencia de personajes y episodios tradicionales que, en general, responden a los grandes hitos de la narrativa maestra nacional. Son frecuentes las propuestas de guion ambientadas en el sitio de Sagunto por parte de Aníbal en el siglo III a.C., la Batalla de Covadonga, la configuración de los reinos cristianos peninsulares (especialmente del Reino de Valencia), los viajes de Colón y la llegada de los españoles a América, la Guerra de Sucesión, la Guerra de la Independencia (con énfasis especial en los fusilamientos del 3 de mayo) o la Transición, entre otros.

Algunos de esos contenidos sólo son enunciados. En el caso de otros, disponemos de información suficiente para valorar la perspectiva historiográfica de nuestros informantes. Así, detectamos un predominio de los enfoques historicistas y positivistas centrados en un modelo de historia descriptiva, protagonizada por grandes personajes o centrada en grandes hechos en los que los Estados-nación tienen un papel protagonista.

Detrás de estos contenidos y enfoques suele haber una finalidad igualmente tradicional a menudo relacionada con el refuerzo de identidades esencialistas que, mediante una perspectiva teleológica, se retrotraen a tiempos muy lejanos. Es habitual también que en un intento de incluir una dimensión crítica, se caiga en un maniqueísmo de corte positivista al intentar que el capítulo dé cuenta de la historia "verdadera" u "objetiva" por oposición a otros enfoques considerados políticos y subjetivos.

Conviene señalar, sin embargo, que, en ocasiones, contenidos en principio clásicos son abordados desde enfoques innovadores. Ése es el caso de una propuesta de guion centrada en la llegada de los españoles a América. En este ejemplo vemos, por un lado, la presencia de una cierta visión esencialista desde el momento en el que se hace referencia a España y a los españoles en el contexto de finales del siglo XV y principios del XVI; no obstante, lo que se persigue es mostrar el impacto de la llegada de una cultura diferente a tierras americanas e intentar ponerse en la piel de la población autóctona. Algo similar sucede con el tratamiento que dos estudiantes hacen de la conquista de Valencia por parte de Jaime I en 1238. Frente a la dimensión identitaria que suele predominar en estos casos, los informantes centran su propuesta de capítulo en el proceso de elaboración de mitos e incluso de fuentes históricas, como la famosa crónica El Llibre dels Feyts, para mostrar al hipotético espectador algunos de los usos y abusos (falseamiento) de la historia:

"El objetivo sería tratar de desmitificar el proceso conocido como 'Reconquista de las tierras valencianas' aclarando las leyendas existentes sobre lo que sucedió" (12, 31 años, mujer).

"Presentaría a Jaume I relatando su crónica, acompañado de episodios flash-backs que demostrarán cómo miente y falsea el rey" (27, 26 años, varón).

Aunque minoritarios, algunos estudiantes centran sus guiones en temas más contemporáneos y/o conflictivos movidos por una clara finalidad crítica. Es el caso de la mayoría de propuestas centradas en la expulsión de los moriscos a principios del siglo XVII, la Segunda República, la Guerra Civil o la emigración española en la postguerra. Con frecuencia estos temas son abordados desde enfoques historiográficos novedosos (historia cultural, estudios de género, historia de la vida cotidiana, historia desde abajo, etc.) y buscan romper con los usos más tradicionales de la historia a partir de propuestas que persiguen desmitificar, problematizar, cuestionar los relatos oficiales, mostrar el proceso de construcción de identidades de distinto signo, fomentar la empatía y el desarrollo de un pensamiento histórico complejo, etc. En algunos casos, el énfasis se pone en la relevancia social del tema y en su posible conexión con el presente; en otros, en el cuestionamiento de un enfoque epistemológico de raíz historicista y positivista que tiende a considerar la 
historia como una disciplina que, a partir del análisis de fuentes, cuenta los hechos "tal y como ocurrieron":

\begin{abstract}
"Compararía dos momentos históricos y los desarrollaría de forma paralela para reflexionar sobre las coincidencias y divergencias de momentos distintos; por ejemplo, la emigración española durante la posguerra y la inmigración actual [...] ¿Cómo podríamos desarrollarlo? Quizás uno de los sujetos históricos del pasado se podría colar en el presente o viceversa. La reflexión sería que quizás los tiempos no han cambiado tanto; se podrían promover valores como la empatía o la tolerancia, al ponerse en el lugar del otro" (54, 24 años, mujer)

“Trabajaría el período de la Restauración [... ] para que se pudiera visualizar el tema del pucherazo y el encasillado [... ] No emplearía personajes históricos, al contrario, lo emplazaría en un entorno local para visualizar cómo muchas veces el voto era comprado con motivo de obtener trabajo y comida estable" (50, 23 años, varón).

"Situaría la acción en el momento de la expulsión de los moriscos desde los puertos del Reino de Valencia. Los agentes del Ministerio del Tiempo tendrían que hacer lo posible para que esa expulsión sí se efectuara. Quizás entonces uno de ellos podría rebelarse contra el Ministerio y comprender que en cada momento del pasado existían ciertas propuestas de futuro que podrían haber sido posibles" (49, 23 años, varón)
\end{abstract}

\title{
Conclusiones
}

Los resultados obtenidos en el presente estudio nos aportan una primera conclusión sobre la representación que el futuro profesorado de Historia tiene acerca de la ficción histórica televisiva como recurso didáctico y como producto cultural. A falta de una ampliación de la muestra, los datos son contundentes y nos aproximan a una mayoritaria visión ilustrativa y descriptiva del relato audiovisual. La mayor parte de los integrantes de la muestra presenta una escasa capacidad de decodificación y de lectura crítica del mismo de cara a comprender los hitos y estereotipos de contenido implícito presentes, singularmente la narrativa nacional como discurso del nacionalismo banal español.

De las respuestas de los docentes en formación se deduce que consumen y valoran el potencial del formato audiovisual, en concreto unas series de televisión que, no podemos olvidar, todavía constituyen el corpus narrativo más potente e influyente en la cultura contemporánea (Buonnano, 1999). Ahora bien, esa valoración positiva no se aleja en gran medida de una concepción epistemológica muy tradicional al defender argumentos meramente positivistas sobre la mayor o menor fidelidad al pasado histórico de las series. No parece importar el contenido implícito en los relatos audiovisuales, sea el protagonismo de determinados hitos del pasado nacional o la visión teleológica del pasado histórico. Parece preocupar más la potencialidad de los relatos para ambientar o contextualizar de forma fidedigna un momento del pasado, olvidando en gran medida la potente representación nacionalizada que pueda hacerse del mismo.

Este déficit del futuro profesorado en alfabetización audiovisual y en formación epistemológica, dificulta las posibilidades futuras de aprovechamiento didáctico crítico de la ficción histórica televisiva. De cara a una mejora de la educación histórica sería necesario introducir cambios en la formación del profesorado en su alfabetización mediática. Una buena vía sería enseñarles a integrar fragmentos de series de televisión de contenido histórico desde un auténtico aprendizaje multimedia (equilibrando todo tipo de recursos, textuales, icónicos y audiovisuales) y, sobre todo, planteando ejercicios que permitan 
impugnar estereotipos del relato nacional y del tiempo histórico que, en último extremo, acaban reforzando el código disciplinar de la historia escolar. No basta, por tanto, con aprovechar y saber emplear estos nuevos recursos didácticos; se hace urgente enseñar a comprenderlos críticamente para integrarlos en la educación histórica básica. En último extremo, también ayudaremos a mejorar la educación ciudadana para el consumo del todavía hegemónico discurso narrativo televisivo.

\section{Bibliografía}

Alfageme, B., Miralles, P. y Monteagudo, J. (2010). Diseño y validación de un instrumento sobre la evaluación de la geografía y la historia en Educación Secundaria. Enseñanza de las Ciencias Sociales. Revista de investigación, 10, 48-60.

Archilés, F. (2015). Nacionalismos y culturas políticas en España (c. 1975-2012). En M. Pérez Ledesma e I. Saz Campos (eds.). Del franquismo a la democracia (1936-2013) (pp. 141174). Madrid: Marcial Pons; Zaragoza: Prensas Universitarias de Zaragoza.

Bel, J.C. (2016). Aprovechamiento de las imágenes en los manuales de historia de educación primaria (1991-2016): evaluación cognitiva y utilización didáctica. Valencia: Universitat de València, Trabajo Fin de Máster de Investigación en Didácticas Específicas, inédito.

Bell, E., Gray, A. (2007). History On Television. Charisma, Narrative and Knowledge. En H. Wheatley (ed.). Re-Viewing Television History. Critical Issues in Television Historiography (pp. 113-133). Londres: I. B. Tauris.

Billig, M. (1995). Banal Nationalism. London: Sage Publications.

Bolufer, M., Gomis, T. y Hernández, T. M. (eds.) (2015). Historia y cine. La construcción del pasado a través de la ficción. Zaragoza: Institución Fernando el Católico.

Buonanno, M. (1999). El drama televisivo. Identidad y contenidos sociales, Barcelona: Gedisa.

Burke, P. (2001). Visto y no visto. El uso de la imagen como documento histórico. Madrid: Crítica.

Carreras, J. J. (ed.) (2003). Usos públicos de la historia. Madrid: Marcial Pons.

Chartier, R. (2007). La historia o la lectura del tiempo. Madrid: Gedisa.

Ferro, M. (2008). El cine, una visión de la historia. Madrid: Akal.

Flick, U. (2007). Introducción a la investigación cualitativa. Madrid: Morata.

Foster, S. (2012). Re-thinking historical textbooks in a globalized world. En M. Carretero, M. Asensio \& M. Rodríguez-Moneo (Eds.), History Education and the Construction of National Identities (pp. 49-62). Charlotte CT: Information Age Publishing.

Giroux, H. (2001). Cultura, política y práctica educativa. Barcelona: Graó.

Gunn, S. (2011). Historia y teoría cultural. Valencia: Servei de Publicacions de la Universitat de València.

Jenkins, K. (2009). Repensar la Historia. Madrid: Siglo XXI.

López Facal, R. (2009). Identificación nacional y enseñanza de la Historia (1970-2008). Historia de la educación, 27, 171-193. 
López Facal, R. y Sáiz, J. (2016). Spain: History Education and Nationalism Conflicts in Spain. En: Guyver. R. (ed.). Teaching History and the Changing Nation State. Transnational and Intranational Perspectives, (pp. 201-215). Londres: Bloomsbury.

Maestro, P. (2005). La idea de España en la historiografía escolar del siglo XIX. En A. Morales, M. Esteban de Vega (eds.). ¿Alma de España? Castilla y las interpretaciones del pasado español (pp. 141-194). Madrid: Marcial Pons.

Martínez Gil, F. (2013). La historia y el cine: ¿unas amistades peligrosas? Vínculos de Historia, 2, 351-372.

McMillan, M. (2010). Juegos peligrosos. Usos y abusos de la Historia. Barcelona: Ariel.

Parra Monserrat, D. (2012). Aprender la patria. El relato nacionalista en la enseñanza de la geografía y la historia de España. Scripta Nova. Revista Electrónica de Geografía y Ciencias Sociales, vol. XVI, 418 (33). En <http://www.ub.es/geocrit/sn/sn-418/sn-41833.htm>

Peris, À. (2012). Nación española y ficción televisiva. Imaginarios, memoria y cotidianidad. En F. Archilés e I. Saz (Eds.). La nación de los españoles. Discursos y prácticas del nacionalismo español en la época contemporánea (pp. 393-418). Valencia: PUV.

Peris, À. (2015). Comunitats catòdiques. La representació de la identitat nacional en la Televisió, Valencia: Universitat de València, tesis doctoral inédita.

Peris, À. (2016). Imaginar la nació a través de la ficció televisiva: memòria, proximitat i vida diària. Debats. Revista de cultura, poder i societat, 130 (1). 31-47.

Rosenstone, R. (1997). El pasado en imágenes. El desafío del cine a nuestra idea de la historia. Barcelona: Ariel.

Rosenstone, R. (2005). La historia en imágenes/la historia en palabras: reflexiones sobre la posibilidad real de llevar la historia a la pantalla, Istor, 20, 91-108.

Rueda Laffond, J.C. (2009). ¿Reescribiendo la historia? Una panorámica de la ficción histórica televisiva reciente, ALPHA, $n^{\circ}$ 29, 85-104.

Rueda Laffond, J.C. (2014). Franquismo banal: España como relato televisivo (1966-1975). En Archilés, F. i Saz, I. (Eds.), Naciones y Estado. La cuestión española (pp. 225-244). València: Publacions de la Universitat de València (PUV).

Rueda Laffond, J.C. y Coronado Ruiz, C. (2009). La mirada televisiva. Ficción y representación histórica en España. Madrid: Fragua.

Rueda Laffond, J.C., Coronado Ruiz, C. (2016). Historical Science Fiction: From Television Memory to Transmedia Memory in El Ministerio del Tiempo. Journal of Spanish Cultural Studies, DOI: 10.1080/14636204.2015.1135601

Rueda Laffond, J.C., Coronado Ruiz, C. y Sánchez, R. (2009). La Historia televisada: una recapitulación sobre narrativas y estrategias historiográficas. Comunicación y sociedad, 12, 177-202.

Rüsen, J. (2005). History: Narration, Interpretation, Orientation. Nueva York: Berghahn.

Sáiz, J. (2015). Educación histórica y narrativa nacional. Valencia: Universitat de València, tesis doctoral inédita.

Sáiz, J., Gómez, C. J. (2016). Investigar el pensamiento histórico y narrativo en la formación del profesorado: fundamentos teóricos y metodológicos. REIFOP, 19 (1), 175-190. 
Sáiz, J., López Facal, R. (2016). Narrativas nacionales históricas de estudiantes y profesorado en formación, Revista de Educación, 374, 118-141.

Seixas, P. y Morton, T. (2013). The Big Six Historical Thinking Concepts. Toronto: Nelson.

Tadeu da Silva, T. (1994) (ed.). O sujeito da educação. Estudos foucaultianos. Rio: Vozes.

Tadeu da Silva, T. (2001). Espacios de identidad. Nuevas visiones sobre el currículum. Barcelona: Octaedro.

Valls, R. (2007). Historiografía escolar española: siglos XIX-XXI. Madrid: UNED.

Wisley, J. y Ash, I.K. (2005). Multimedia Learning of History. En R. Mayer (ed.), The Cambridge Handbook of Multimedia Learning (pp. 375-392). Nueva York: Cambridge University Press. 